\title{
Cervical Dumbbell Ganglioneuroma Causing Quadriplegia
}

\author{
Obande J O, 'Dawang Y D, ${ }^{1}$ Otorkpa E J, ${ }^{1}$ Okpanachi C I, ${ }^{1}$ Obande E I \\ ${ }^{\prime}$ Division of Neurosurgery, Department of surgery and ${ }^{2}$ School of Post-Basic Critical Care Nursing, of University of Abuja Teaching \\ Hospital, Abuja. \\ *Correspondence: Obande JO. University of Abuja Teaching Hospital, Abuja \\ Phone: +234(0)8033011882 \\ Email: obandejo@yahoo.com

\begin{abstract}
Article information
Date Submitted: $\quad 2 / 1 / 2021$

Date Accepted: $\quad$ 17/6/2021
\end{abstract} \\ Date Published: $\quad 30 / 6 / 2021$
}

\begin{abstract}
Ganglioneuroma is a rare benign tumour that originates from the ganglion cells of the sympathetic nervous system. They are rare in cervical spine region and only $8 \%$ of ganglioneuromas occur in the neck. The common sites of occurrence are in the posterior mediastinum, retroperitoneum and adrenal medulla, and as such, a cervical occurrence presenting with quadriplegia is a reportable event. We present a 26-year old young male with a two-year history of neck pain and progressive quadriplegia. He later became wheelchair-bound. Musculoskeletal examination revealed multiple generalized nodular skin swellings with café au lait macules. Magnetic resonance imaging showed a huge dumbbell tumour of the first two cervical vertebrae, to the right side of the spinal canal causing significant spinal cord compression. He had surgical intervention, aimed at complete tumour resection, postoperatively, power of the limbs improved to normal. Histological examination was consistent with ganglioneuroma. We present this report because the occurrence of ganglioneuroma is rare, secondly a cervical presentation is unusual and thirdly it presented as a rare cause of quadriplegia.
\end{abstract}

Keywords: Cervical spine tumour, Ganglioneuroma, Spinal cord compression, Sympathetic nervous system

\section{INTRODUCTION}

$\mathrm{G}$ anglioneuromas are benign tumours that originate from the ganglion cells of the sympathetic nervous system and adrenal medulla. ${ }^{1}$ They most commonly present in the second decade of life, though, they can occur after the age of three years and affect females more. ${ }^{2,3}$ The common sites are the posterior mediastinum, retroperitoneum and adrenal medulla, ganglioneuromas

How to cite this article

Obande J O, Dawang Y D, Otorkpa E J, Okpanachi C I, Obande E I. Cervical Dumbbell Ganglioneuroma Causing Quadriplegia. J Biomed Res Clin Pract:2021;4(1):47-51 DOI.10.46912/jbrcp.203. are rarely found in the cervical spine region. ${ }^{4,5,6,7}$ Only $8 \%$ of ganglioneuromas occur in the neck. ${ }^{8}$ These sporadic tumours, may also present as part of multiple endocrine neoplasias associated with Neurofibromatosis type 1, NF1, otherwise called Von Recklinghausen's disease.,10

Ganglioneuroma arising from the cervical sympathetic chain in relation to a cervical nerve may demonstrate 
mass effect causing radiculopathy or myelopathy and weakness of extremities. This is a rare differential in an adult patient with neck pain and limb weakness. ${ }^{11}$ Only 10 cases of cervical ganglioneuromas have been documented in the world literatures as of $2014 .^{12}$ There has been no documentation of any case of cervical spine ganglioneuroma in the Nigerian literature to the best of our knowledge. Hence, we report this case of a 26-year old man with cervical spine ganglioneuroma, which is rare, occurring in an unusual site with unusual presentation; and having features of Von Recklinghausen's disease.

\section{CASE REPORT}

A 26-year old man had presented with neck pain and weakness of both upper and lower limbs of two years duration. The pain limited neck movement. Weakness was worse on the lower limbs than in the upper limbs and affecting the right side than the left. A week before the presentation he was unable to walk and became confined to a wheelchair. There was associated history of generalized headache and slurred speech. He had no sphincteric symptoms nor paresthesia. Eighteen years prior to presentation, he noticed some dark spots on his skin with multiple progressively increasing, painless and non-itchy nodular swellings that were more on the trunk and the upper limbs. There was the history of similar swellings in his patrilineal cousin. He was not a known hypertensive. On examination, he was conscious with significant findings in the neurological and musculoskeletal systems. Motor-power in the right upper limb was $1 / 5$, right lower limb 2/5, left upper limb 2/5, left lower limb 3/5. There were reduced tones of the muscles globally. Eye examination revealed normal lids and lashes. Normal conjunctival and sclera. Reddish spots on both irises, suggestive of Lisch nodules. Musculoskeletal examination revealed multiple nodular skin swellings on the back, neck and upper limbs. Multiple >10 hyperpigmented macular skin lesions. No axillary freckles. There was reduced muscle bulk of all limbs. Spine examination was normal. A diagnosis of flaccid quadriplegia secondary to cervical spinal cord compression with background neurofibromatosis type 1 was made. Cervical magnetic resonance imaging showed a dumbbell tumour of the $\mathrm{C} 1$ and $\mathrm{C} 2$ with the largest part in the extra spinal canal and the intraspinal segment abutting on the anterior spinal cord in the region of $1^{\mathrm{ST}}$ and 2nd cervical vertebrae. He was prepared for and had partial right laminectomy of the $\mathrm{C} 2$ vertebra and complete tumour resection and complete decompression of the spinal cord. The Postoperative period was uneventful, with the patient recovering all limb functions within one month of the surgery. The resected specimen was histologically diagnosed as a Ganglioneuroma.

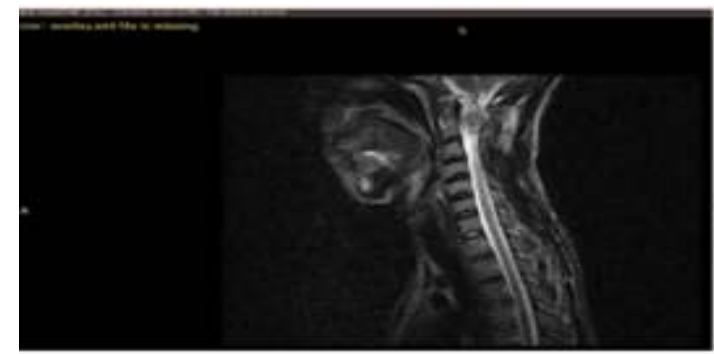

A. Mid-sagittal T2-weighted image showing hypointense $\mathrm{C} 1 / \mathrm{C} 2$ tumour

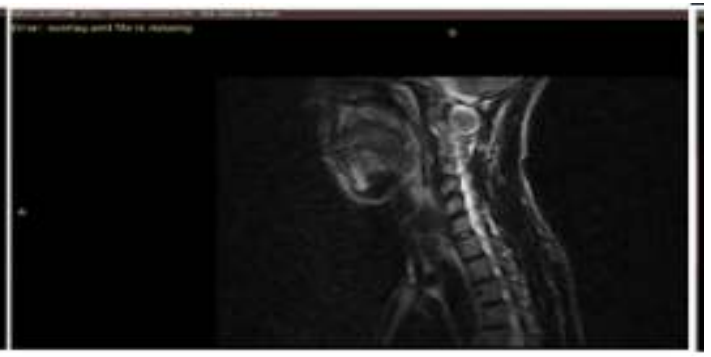

B. A right parasagittal T2-weighted image the predominant extradural component of tumour

Fig. 1: Preoperative magnetic resonance imaging of the patient. 


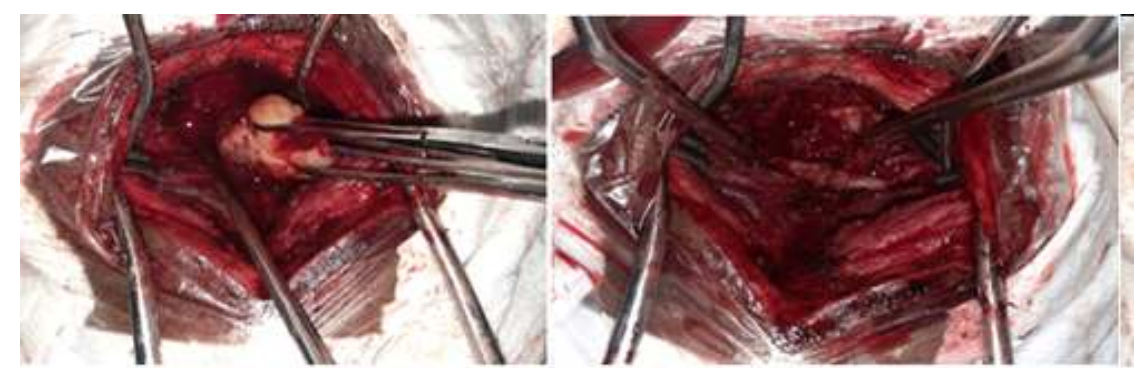

A. Image showing extradura tumour before excision

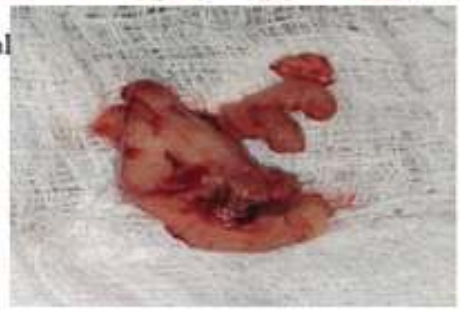

C. Image showing excised tumour
B. Image showing tumour bed post-excision

Fig. 2: Intraoperative images revealing the tumour and excised tumour of the patient.

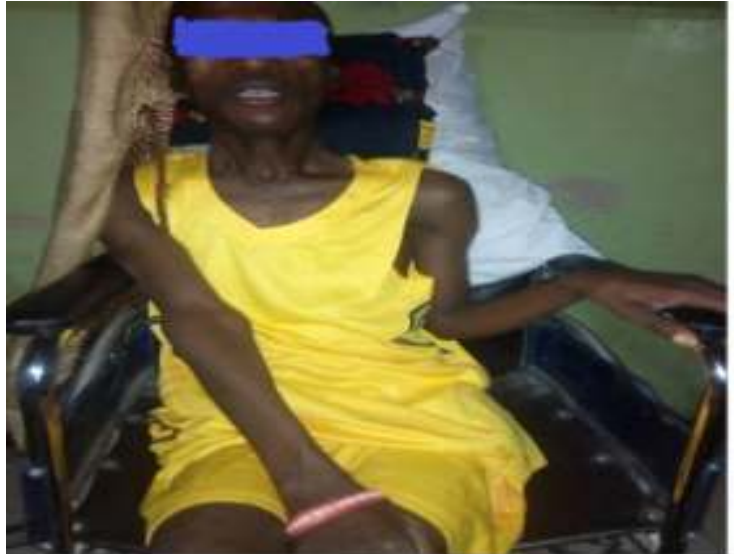

A. The patient at presentation quadriplegic.

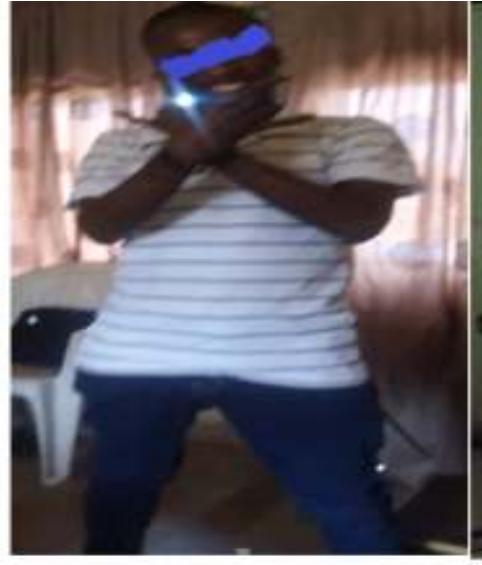

B. The patient two months after surgery.

Fig. 3: Patient's images (A) preoperatively wheelchair-bound and (B) a happy patient postoperatively. 


\section{DISCUSSION}

Following the first description of ganglioneuroma by Loretz in 1870 and the establishment of its occurrence and distribution along with the sympathetic ganglia, de Quervain then went on to describe the first cervical ganglioneuroma, 29 years later, in $1899 .{ }^{13}$ Up till 2014, only 9 cases have been documented in the literature. ${ }^{12}$ They are slow-growing benign tumours of the sympathetic nervous system. ${ }^{1}$

Cervical localization of a ganglioneuroma is one of its least common sites of occurrence. ${ }^{4,5,6,7}$ This is actually, one of the rarest neck tumours ${ }^{8}$, more commonly seen in the abdomen or thorax. They are more common among the young, as $60 \%$ of patients with ganglioneuroma are $<20$ years old. ${ }^{12}$

Ganglioneuromas are slow-growing tumours, and clinically become manifest due to pressure symptoms or compression of adjacent structures. ${ }^{8}$ Our patient presented with quadriplegia from compression of the upper cervical spinal cord. There was also change in voice, with slurring of speech, which may be due to the cervical tumour expansion compressing on the larynx and recurrent laryngeal nerve. ${ }^{8}$ The presence of Lisch's nodules and other characteristics of neurofibromatosis type $1-\mathrm{NF} 1$ were equally present in our patient. NF1 is an autosomal dominant disease with an incidence rate of 1 in 3000 persons. ${ }^{12} \mathrm{NF} 1$ being one of the most common genetic disorders has a wide clinical spectrum, with multisystem involvement, however, neural involvement determines its prognosis. ${ }^{12}$ Our patient had lived with the generalized neurofibromas for 18 years but had to present due to the quadriplegia, indicating neural involvement. Foramen magnum and upper cervical masses present with suboccipital headache and clumsiness of the intrinsic muscle of the hands as in the case of upper cervical ganglioneuroma. ${ }^{14}$ The cause of this presentation is presumed to be due to venous insufficiency at the spinomedullary junction.

The review of literature had suggested a probable secretory nature of ganglioneuroma; however, most articles have not found this to be so. ${ }^{8}$ Our case was not metabolically active, in keeping with other studies. ${ }^{8}$

The diagnostic utility of radiological imaging studies was of immense value in not only elucidating the differential diagnoses but also in surgical planning. To this end, the CT scan revealed a well-circumscribed $\mathrm{C} 1 / \mathrm{C} 2$ mass displacing surrounding structures and the MRI showing intermediate signal intensity and non-homogenous contrast enhancement. ${ }^{15}$

Surgical resection of these tumours is the gold standard treatment ${ }^{8}$ and the tumour is well-encapsulated. ${ }^{16}$ Due to its location, a posterior midline spinal approach was employed, and coupled with partial laminectomy. This was sufficient for surgical excision of the tumour as most of the dumbbell tumour was extradural. Both the intradural and extradural portions were causing spinal cord compression. However, the intradural portion was only minimal, this was so because the origin of the ganglioneuroma was from the sensory root ganglia located extracanalicular ${ }^{12}$, leaving a very large extradural portion. This was easily resected leaving a bleb of the arachnoid at the dura opening. The minimal structural manipulation permitted minimal morbidity as there was no injury to nearby neural and vascular structures. The patient regained the use of all limbs within a month of the surgical intervention. Surgical excision may be considered curative after histological confirmation of the tumour as a ganglioneuroma ${ }^{8}$ Thus, the prognosis is favourable, as ganglioneuromas do not have metastatic potential. ${ }^{8}$ As such no further treatment is required, even with incomplete excision, as it has poor potential to recur. ${ }^{17}$

Ganglioneuromas are known to occur in the syndromes of multiple endocrine neoplasias (MEN) type 2B and NF1. ${ }^{18}$ Therefore, our patient who had a positive family history will require further study to unravel the association.

\section{CONCLUSION}

Although the diagnosis of ganglioneuroma is uncommon, more so, a cervical ganglioneuroma, the neurologist, 
neurosurgeon and other physicians need to be aware of this diagnosis in a young patient with neck pain presenting with quadriplegia. Asymptomatic paraspinal ganglioneuroma when appropriately diagnosed, definitive treatment with surgical resection, offers a good outcome. The relief of symptoms is very rewarding to the patient.

\section{Conflict of Interests}

The authors declare that they have no conflicts of interests.

\section{REFERENCES}

1. Belzberg AJ, Campbell JN. Neoplasms of peripheral nerves. In: Wilkins RH, and Rengachary SS, editors. Neurosurgery: Vol: 11l, 2nd Ed. New York: Mc Graw-Hill 1996:3217 - 3223.

2. Weeler R, Cervos-Navarro J. Pathology of peripheral nerves. White friars Press. London, England: 1997. 190-198.

3. Reschini E, Catania A, Airaghi L, et al. Scintigraphic study of extra adrenal ganglioneuroma in a patient with overlap between multiple endocrine neoplasia types 1 and 2. Clin Nucl Med.1992; 17:573-576.

4. Levy Dl, Bucci MN, Weatherbee L, et al. Intradural extramedullary ganglioneuroma: case report and review of the literature. Surg Neurol. 1992 ;37 :21 6218.

5. Shotton JC, Milton CM, Allen JP. Multiple ganglioneuromas of the neck. J Laryngol Otol.'1992; 106: 277-278.

6. Armstrong P, Wilson A. lmaging of disease of the chest. London England. Mosby. 1995: 7 62-7 68.

7. Marchevesky A. Mediastinal tumours of Peripheral nervous system origins. Semin Diagnostic Pathology.1999; 16: 65-78.

8. Lima AF, Moreira FC, Menezes A, Dias L. Cervical Ganglioneuroma in Pediatric Age: A Case Report. Turk Arch Otorhinolaryngol. 2018;56(4):237-240. doi:10.5152/tao.2018.3690
9. Kyoshima K, Sakai K, Kanaji M, et al. Symmetric, dumbbell ganglioneuromas of bilateral C-2 and C-3 roots with intradural extension associated with Von Recklinghausen's disease. Surg Neurol 2004, 61 (5): 468 - 474.

10. Torre M, Martucciello G, Geccherini I, et al. Diagnostic and therapeutic approach to multiple endocrine neoplasia type 2 in pediatric patients. Pediatr Surg lnt. 2002, 18 (5-6): 378 - 383.

11. Claifo L, Zulpi A, Mangone GM, et al. Ganglioneuroma: report of a case. Otolaryngology Head Neck Surgery, 2001;124 (1): 115-116.

12. Hioki A, Miyamoto K, Hirose Y, Kito Y, Fushimi K, Shimizu K. Cervical symmetric dumbbell ganglioneuromas causing severe paresis. Asian Spine J. 2014;8(1):74-78. doi:10.4184/asj.2014.8.1.74

13. Lima AF, Moreira FC, Menezes A, Dias L. Cervical Ganglioneuroma in Pediatric Age: A Case Report. Turk Arch Otorhinolaryngol. 2018;56(4):237-240. doi:10.5152/tao.2018.3690

14. McCormick PC and stein BM. Spinal cord tumours in adults. In: Yeomans JR, editor. Neurological surgery. Vol 4, 4th Ed, Philadelphia. W.B Saunders. 1996: 31 02-3122.

15. Fumikazu S. Intrathoracic neurogenic tumours: MR, pathologic correlation. Am J Roentgenol 1992; 159:279-283.

16. Ugarriza LF, Cabezudo JM, et al. Bilateral and symmetric C-1 - C-2 dumbbell ganglioneuroma producing severe spinal cord compression. Surg Neurol, 2001 ;55 (4): 228 - 231.

17. Stein BM, Leeds NE, Taveras JM, et al. Meningiomas of the foramen magnum. J Neurosurgery 1963; 20: 740-751.

18. Hergunsel, O.B., Demir, F., Akin, M.M. et al. Myelopathy due to bilateral symmetrical dumbbell cervical ganglioneuroma in a pediatric neurofibromatosis type 1 patient and rigid posterior instrumentation - a case report. Egypt J Neurosurg 2019; 34 (12) https://doi.org/10.1186/s41984-0190038-7. 